\title{
Comparative Evaluation of the Efficacy of Hand-Wrist and Cervical Vertebrae Radiography for the Determination of Skeletal Age
}

\author{
Mohammadhashem Hoseini, ${ }^{1}$ Sara Zamaheni, ${ }^{2}$ Hourieh Bashizadeh Fakhar, ${ }^{3}$ Forough Akbari, ${ }^{4}$ Javad \\ Chalipa, ${ }^{1}$ and Afsaneh Rahmati ${ }^{2, *}$ \\ ${ }^{1}$ Department of Orthodontic, School of Dentistry, Tehran University of Medical Sciences, Tehran, Iran \\ ${ }^{2}$ Department of Endodontics, School of Dentistry, Shahid Beheshti University of Medical Sciences, Tehran, Iran \\ ${ }^{3}$ Department of Radiology, School of Dentistry, Tehran University of Medical Sciences, Tehran, Iran \\ ${ }^{4}$ Department of Pediatrics, School of Dentistry, Shahid Beheshti University of Medical Sciences, Tehran, Iran \\ "Corresponding author: Afsaneh Rahmati, Department of Endodontics, School of Dentistry, Shahid Beheshti University of Medical Sciences, Tehran, Iran. Tel: +98-2122403080, \\ Fax: +98-2122403194, E-mail: drrahmati@ymail.com
}

Received 2014 September 10; Revised 2015 May 27; Accepted 2015 June 20.

\begin{abstract}
Background: Prediction of skeletal growth is necessary for growth modification and surgical orthodontic treatments and is usually done by assessing skeletal maturity indicators in hand-wrist radiographs. The use of growth stages of cervical vertebrae in lateral cephalograms has been suggested to avoid overexposure.

Objectives: This study seeks to assess the degree of agreement between hand-wrist and cervical vertebrae maturation stages for skeletal age determination and prediction of the peak growth spurt (PGS).

Patients and Methods: This cross-sectional study was conducted with 67 boys and 66 girls between 8 and 18 years of age, divided into 11 age groups; 266 hand-wrist radiographs and lateral cephalograms were obtained and analyzed. Hand-wrist maturation stages were evaluated according to the Grave and Brown, Bjork system (stages 1 - 9). The cervical vertebral maturation stage (CVMS) was determined on lateral cephalograms based on a system described by Baccetti et al. (CVMS 1-5). To apply the Cohen's kappa index, the stages of growth were reduced to 5 intervals (A-E) to relate the 5 CVMS to the 9 stages of Bjork hand-wrist analysis.

Results: In all age groups, the skeletal maturity stages of the hand and wrist bones and the cervical vertebrae of the girls were ahead of the boys. Cohen's kappa test revealed a low level of agreement between the two methods [Kappa $(95 \% \mathrm{CI})=0.312(0.290$ 0.377)]; concordance was slightly higher in males ( $\mathrm{K}=0.33$ for males versus 0.27 for females). Evaluation of concordance coefficients between the stages determined by the two methods indicated the highest concordance in 8- and 9-year-olds and the lowest in 12and 14-year-olds. The level of agreement between the two methods was only acceptable in 8- and 9-year-olds of both genders and 10-year-old boys. The level of agreement between the two methods in other age groups was not acceptable.

Conclusion: The level of agreement between the two methods was low; thus, they cannot be used alternatively to estimate patients' skeletal age or to predict the PGS. This may be due to the effect of different maturation levels (influenced by the environment, ethnicity, and gender) on the agreement between methods for skeletal age determination.
\end{abstract}

Keywords: Growth, Hand, Wrist, Cervical Vertebrae, Skeletal Age

\section{Background}

The prediction of facial growth may be the most critical aspect of clinical orthodontics for a large number of patients. Although the number of adult orthodontic patients has increased in recent years, most orthodontic treatments are provided to prepubertal and pubertal patients (1).

Growth modification appliances such as functional appliances and extra-oral devices (namely headgear, face masks, Herbst appliances, etc.) should be used during the peak velocity of growth. On the contrary, orthognathic surgery can be performed only after the pubertal growth spurt because considerable post-surgical growth can cause relapse. Significant mandibular growth occurs during the peak growth spurt (PGS). PGS depends on gender and the chronological age of patients; it usually occurs between the ages of $10-12$ years in girls and $12-14$ years in boys. The growth periods mentioned are the most important for orthodontic treatments. Studies have shown that chronological age alone is not sufficient for the assessment and prediction of mandibular growth or the degree of skeletal maturation, which is the most important indicator of mandibular growth (2-8).

In orthodontics, skeletal age is used to determine the 
remaining growth. Several methods have been suggested for skeletal age determination, including assessment of cervical vertebrae (9-15), hand-wrist bones $(3,5,13,15,16)$, and frontal sinus (17) maturation.

Fishman (4) introduced the skeletal maturation index (SMI) for the assessment of skeletal growth based on the maturation of hand and wrist bones. In this method, 4 stages of ossification at 6 anatomical sites of the hand and wrist (thumb, $3^{\text {rd }}$ finger, $4^{\text {th }}$ finger and radius) are evaluated. Hand-wrist radiography is commonly used for determination of skeletal maturation due to the presence of various bones in this area. The only shortcoming, according to some experts, is the complexity of differentiating landmarks that can lead to an incorrect prediction of growth. Therefore, it has limited value for the prediction of growth. Another drawback is the high exposure dose for patients (18).

Assessment of the cervical vertebral maturation (CVM) is another method for the evaluation of skeletal maturity $(8,10-15)$. This method has yet to be fully evaluated. However, it appears to have high potential for the determination of skeletal age.

Study of changes in the shape and size of cervical vertebrae goes back to the early $20^{\text {th }}$ century. Todd and Pyle (19) evaluated the developmental changes in cervical vertebral dimensions using lateral cephalograms.

In 1972, Lamparski (9) invented a method of skeletal maturity assessment based on morphological changes of C1- C6.

In 1995, Hassel and Farman (11) evaluated the lateral cephalograms and left hand-wrist radiographs of 220 subjects at the Case Western Bolton-Brush Growth Study Center to study the changes in the vertebral body of $\mathrm{C} 2, \mathrm{C} 3$ and C4 and to classify the morphological changes of the cervical vertebral body in relation to SMI. The advantage of this method is that it evaluates $\mathrm{C} 2, \mathrm{C} 3$, and $\mathrm{C} 4$, which are visible even when the patient wears radiation protection such as a lead thyroid collar. They confirmed the results of Lamparski and concluded that this method can be applied for predicting the remaining growth in orthodontic patients.

In 2002, Baccetti et al. (10) proposed the cervical vertebral maturation stage (CVMS) system. They evaluated radiographs of patients and found no significant difference between cervical vertebral stage (CVS) I and II (which were separate in the original CVM system). The concavity at the lower border of C2 is not an exclusive characteristic of CVS II when compared to CVS I. Thus, the two stages of CVS I and II were merged into CVMS I.

In order to prevent overexposure and to overcome the limitations of hand-wrist radiographic assessment, the CVM system was suggested.

\section{Objectives}

This study aims to answer the question of whether the CVMS can replace hand-wrist radiographic assessment for the determination of skeletal maturity or the prediction of growth spurts in patients in clinical settings. Figure 1 shows the stages of the study.

\section{Patients and Methods}

The understudy subjects were between 8 and 18 years old. The inclusion criteria were:

- No history of severe systemic disease.

- No history of long-term drug intake.

- No hormonal, metabolic, or hereditary disorders.

- No history of trauma to the head or neck area.

- Need skeletal age assessment (by hand-wrist radiography) as a sequence of orthodontic treatment (which requires a lateral cephalogram) to not obtain any extra radiographs.

A total of 133 patients who were referred to the orthodontic department of the dental school at the Tehran University of Medical Science in 2012 were selected using consecutive convenience sampling. Informed consent was obtained from them and their parents. A right hand-wrist radiograph was obtained from each patient. There is no difference between the radiographic geometry of digital and conventional radiographs or the shape of vertebrae and other bones used in this analysis in both images, so conventional radiography was applied. Radiographs were obtained using a CC Proline Panoramic Cephalometric X-ray unit (Planmeca, Finland) and Kodak film with exposure settings of $4 \mathrm{~mA}, 60 \mathrm{kVp}$ potential difference, $0.2 \mathrm{~s}$ exposure time, and a 5 central symmetric collimator. The hand was placed over the film in a clenched-fist position. A lateral cephalogram was also obtained with exposure settings of $12 \mathrm{~mA}, 68 \mathrm{kVp}$ potential difference, 0.6 - 0.8 seconds exposure time, and a 4 vertical asymmetric collimator at the same time. The chronological age of the patients was determined based on their date of birth printed on their birth certificates and also by questioning their parents. Radiographs were placed on a negatoscope and evaluated by a radiologist in a darkroom. The maturation stage of the hand and wrist bones was determined according to the Grave and Brown, Bjork system (stages 1 - 9) in 7 anatomical sites in the hand and wrist (Figure 2 and Table 1$)(20,21)$.

The maturation stage of the cervical vertebrae was determined according to the system described by Baccetti et al. (10) (stages 1-5) based on the morphology of C2, C3, and C4 (Figure 3 and Table 2). All analyses were repeated by the same examiner 6 months later to confirm their accuracy. 


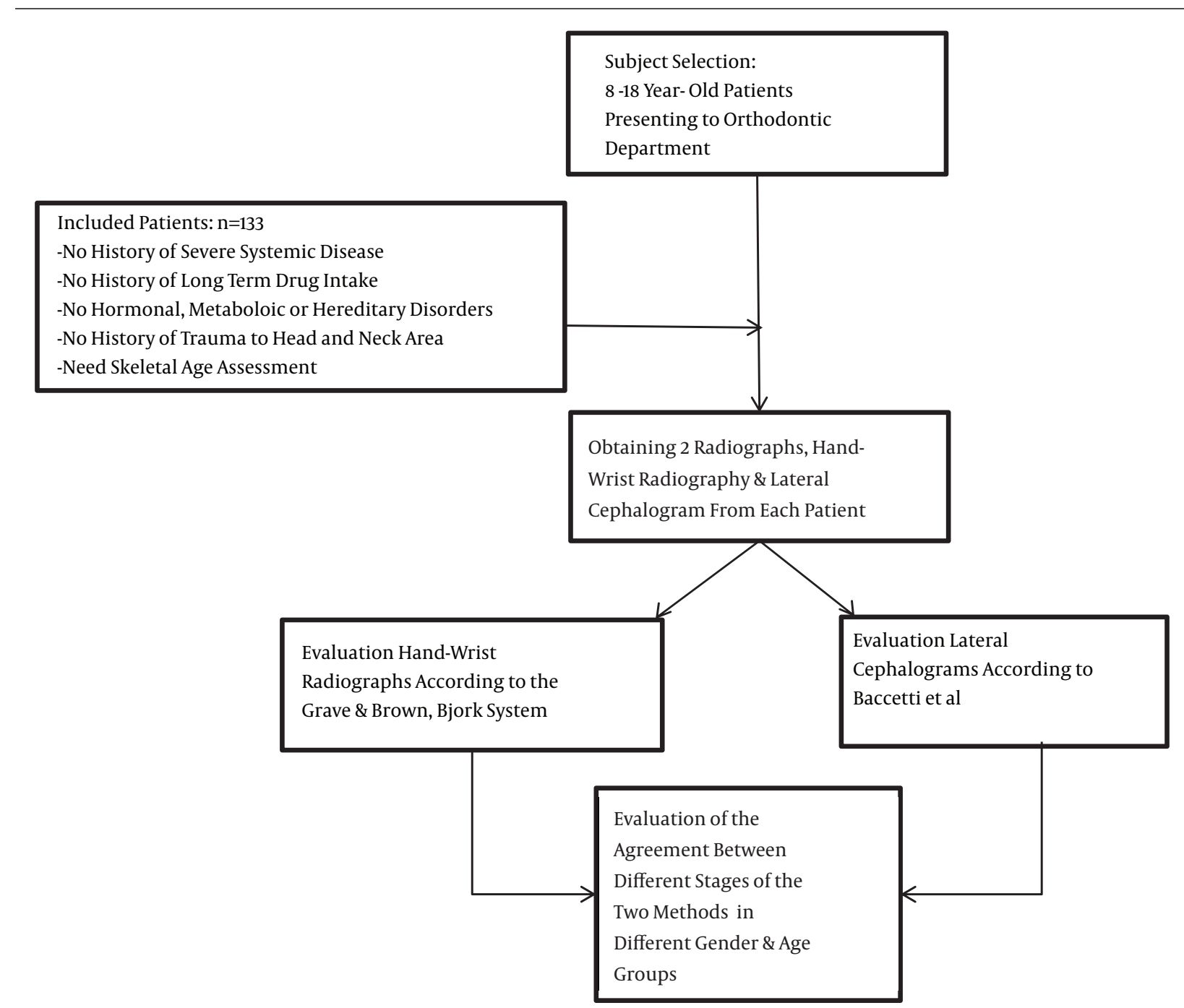

Figure 1. STARD flow chart of the methodology employed

In order to determine the correlation between the maturation stage determined by the Bjork index and the CVMS in each age group, the concordance coefficient was calculated and used for the comparison of the two methods. Cohen's Kappa index was applied to determine the skeletal maturation stage (CVMS, Grave and Brown, Bjork). The second assessment, performed 6 months later, confirmed the primary results. To apply Cohen's kappa index, the stages of growth were reduced to 5 intervals (A-E) to relate the 5 CVMSs to the 9 stages of Bjork hand-wrist analysis (Table 3 ).

It should be noted that reducing the stages from 9 to 5 does not result in the loss of a considerable amount of information (22) because the goal is not to compare each and every stage of the two methods but to determine the intervals with the most important and influential growth events.

Data were analyzed using SPSS version 16 , STATA version 14 , and Cohen's kappa index with a confidence interval of $95 \%$.

\section{Results}

Evaluation of the maturation stage of the hand-wrist bones of patients in all age groups, in 67 boys and 66 girls who were referred to the orthodontic department from October 2012 until August 2013, revealed that the girls were ahead of the boys of the same age (Table 4). 


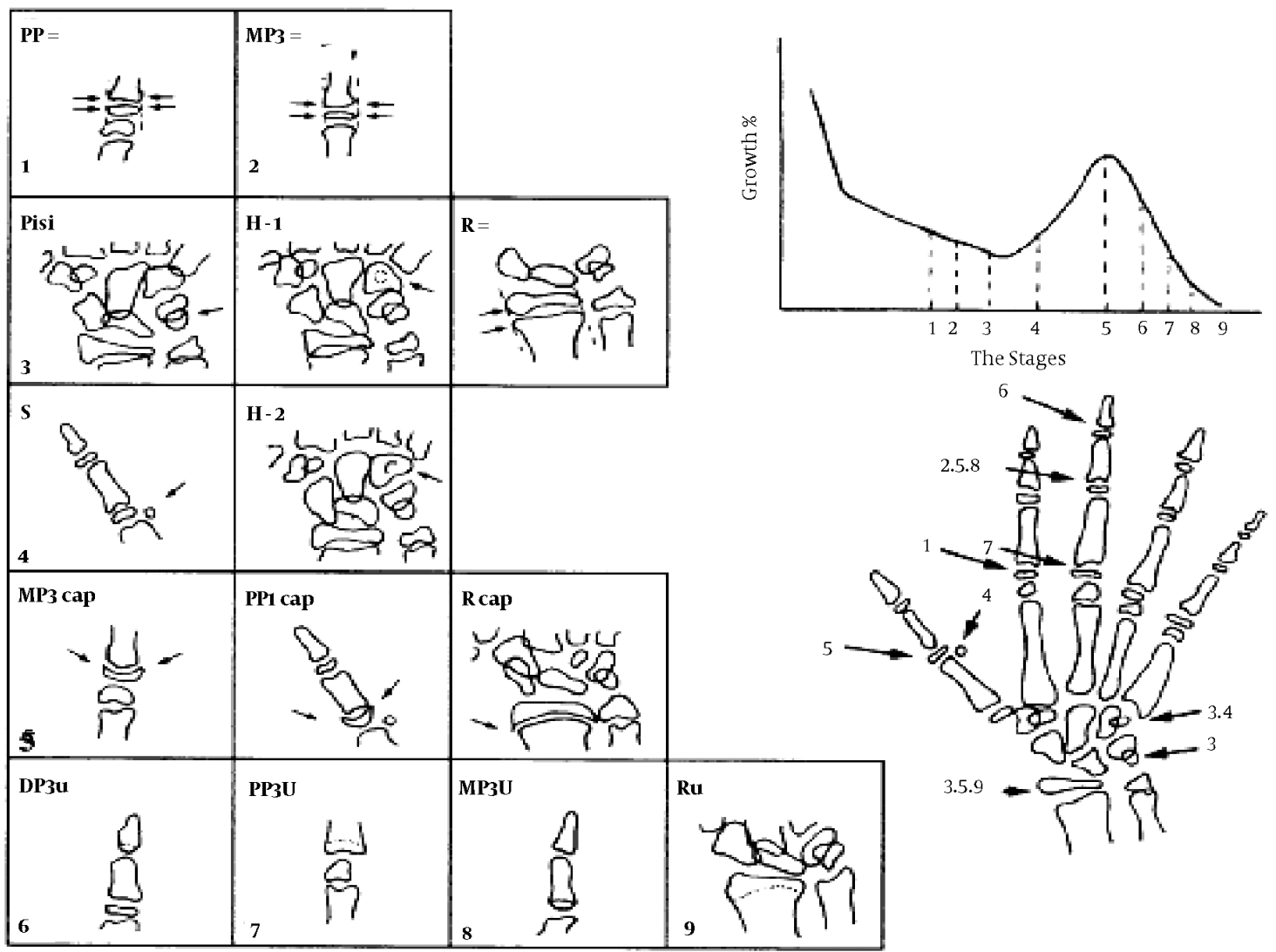

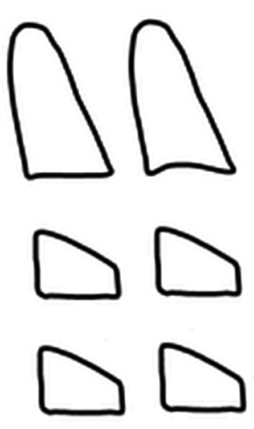

CVMS I
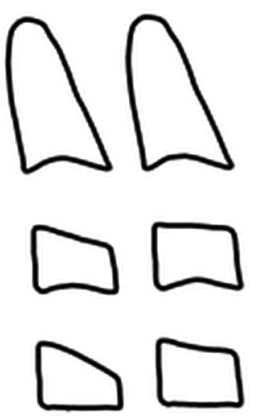

CVMS II
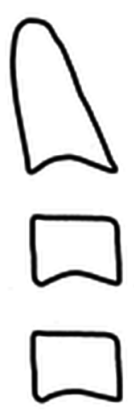

CVMS III
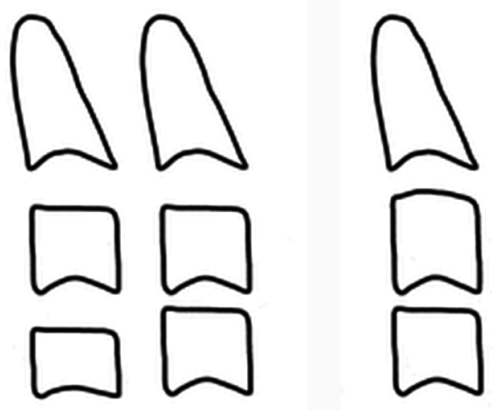

CVMS IV

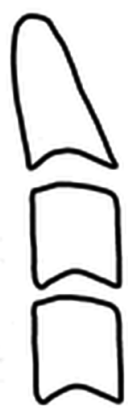

CVMS V

Figure 3. The 5 cervical vertebral maturation stages (CVMS) (Baccetti et al.) (10)

Evaluation of the maturation stage of cervical vertebrae in all age groups revealed that girls were ahead of boys of the same age (Table 5).

To assess the degree of concordance between the hand- 
Table 1. The 9 Maturation Stages of the Hand and Wrist Bones (Brown \& Grave, Bjork) and the Correlation Between Them and Skeletal Age

\begin{tabular}{|c|c|c|c|}
\hline Stages & Description & Boys' Skeletal Age & Girls' Skeletal Age \\
\hline Stage 1 (Proximal phalanx of index finger) & $\begin{array}{l}\text { Epiphysis and diaphysis of the proximal phalanx of the index } \\
\text { finger are equal. This stage occurs approximately } 3 \text { years earlier } \\
\text { than the pubertal growth spurt. }\end{array}$ & 10.6 & 8.1 \\
\hline Stage $2\left(\right.$ Middle phalanx of the $3^{\text {rd }}$ finger $=$ MP3 $)$ & $\begin{array}{l}\text { The epiphysis and diaphysis of the middle phalanx of the middle } \\
\text { finger are equal. }\end{array}$ & 12.0 & 8.1 \\
\hline Stage 3 (Pisi, H1, R) & $\begin{array}{l}\text { This stage is identified by three distinct ossification areas. They } \\
\text { demonstrate individual variations but appear at the same time } \\
\text { during the maturation process. Pisi-stage: Initiation of } \\
\text { calcification in Pisiform bone. H1-stage: Calcification of the } \\
\text { Hamular process of the medial pterygoid plate in the sphenoid } \\
\text { bone. R-stage: The epiphysis and diaphysis of the radius bone are } \\
\text { equal. }\end{array}$ & 12.6 & 9.6 \\
\hline Stage 4 ( $\mathrm{S}$ and $\mathrm{H} 2$ stage) & $\begin{array}{l}\text { This stage occurs just before or at the initiation of the pubertal } \\
\text { growth spurt. S-stage: Primary mineralization of the ulnar } \\
\text { sesamoid bone of the metacarpophalangeal joint of the thumb. } \\
\text { H2-stage: Advanced calcification of the Hamular process of the } \\
\text { sphenoid bone. }\end{array}$ & 13.0 & 10.6 \\
\hline Stage 5 (MP3cap, PP1cap, Rcap stage) & $\begin{array}{l}\text { The peak of growth spurt. MP3cap stage: Cap-like calcification of } \\
\text { the middle phalanx of the third finger. PP1cap stage: Cap-like } \\
\text { calcification at the proximal phalanx of the thumb. Rcap-stage: } \\
\text { Cap-like calcification in the radius bone }\end{array}$ & 14.0 & 11.0 \\
\hline Stage 6 (DP3u stage) & $\begin{array}{l}\text { Visible union of epiphysis and diaphysis at the distal phalanx of } \\
\text { the middle finger ( } 3^{\text {rd }} \text { finger) }\end{array}$ & 15.0 & 13.0 \\
\hline Stage 7 (PP3u stage) & $\begin{array}{l}\text { Visible union of epiphysis and diaphysis at the proximal phalanx } \\
\text { of the middle finger }\end{array}$ & 15.9 & 13.3 \\
\hline Stage 8 (MP3u stage) & $\begin{array}{l}\text { Visible union of the epiphysis and diaphysis at the middle } \\
\text { phalanx of the middle finger is clearly seen. }\end{array}$ & 15.9 & 13.9 \\
\hline Stage 9 (Ru stage) & $\begin{array}{l}\text { Complete union of the epiphysis and diaphysis of the radius. All } \\
\text { the hand bones are completely calcified and skeletal growth is } \\
\text { completed. }\end{array}$ & 18.5 & 16 \\
\hline
\end{tabular}

Table 2. The 5 CVMSs Described by Baccetti et al. (10)

\begin{tabular}{ll}
\hline CVMSs & Description \\
\hline CVMS I: & $\begin{array}{l}\text { The inferior borders of C2, C3, and C4 are flat. There is a 50\% possibility of a concavity at the lower border of C2. The bodies of C3 and C4 are trapezoid in } \\
\text { shape with the superior border tapered from posterior to anterior. The peak of mandibular growth will occur no earlier than one year after this stage. }\end{array}$ \\
CVMS II: & $\begin{array}{l}\text { Concavities at the lower borders of both C2 and C3 are present. C3 and C4 may be trapezoidal or rectangular in shape. The peak of mandibular growth will } \\
\text { occur within one year after this stage. }\end{array}$ \\
CVMS III: & $\begin{array}{l}\text { Concavities at the lower borders of C2, C3, and C4 are present. C3 and C4 are rectangular horizontal in shape. The peak in mandibular growth has occurred } \\
\text { one or two years before this stage. }\end{array}$ \\
CVMS IV: & $\begin{array}{l}\text { Concavities at the lower borders of C2, C3, and C4 are clearly seen, and at least one of the bodies of C3 and C4 is square in shape; if not, the bodies of the } \\
\text { remaining cervical vertebrae are still rectangular horizontal in shape. The peak of mandibular growth has occurred no more than one year before this } \\
\text { stage. }\end{array}$ \\
CVMS V: & $\begin{array}{l}\text { The concavities at the lower borders of C2, C3, and C4 are still evident. At least one of the bodies of C3 and C4 is rectangular vertical in shape; if not, the } \\
\text { bodies of the remaining vertebrae are square in shape. The peak in mandibular growth has occurred no more than two years before this stage (10). }\end{array}$ \\
\hline
\end{tabular}

Abbreviation: CVMS, cervical vertebral maturation stage.

wrist bone maturation stages (5 stages) and CVMS (5 stages), Cohen's kappa index was calculated to be 0.312 . These stages had a $46.7 \%$ degree of agreement that indicates poor concordance between the two methods. The Kappa index was 0.27 among the 66 girls and 0.33 among the 67 boys in our study, which indicates slightly higher concordance between the two methods in boys (Table 6).

Evaluation of the agreement between different stages of the two methods in different age groups revealed that the highest agreement was in the 8-(90\%) and 9-(0.78) yearolds and the lowest agreement was in the age groups of 12and 14-years old (18\%) (Table 7). 
Table 3. Five Intervals (A-E) to Relate the 5 CVMSs to the 9 Stages of Bjork Hand-Wrist Analysis

\begin{tabular}{ll}
\hline Intervals & Description \\
\hline Interval A & Growth stages before the pubertal growth spurt peak that correspond to Bjork stages 1-3. \\
\hline Interval B & Growth acceleration stage until reaching the peak; it corresponds to Bjork stage 4. \\
\hline Interval C & Stage of peak growth that corresponds to Bjork stage 5. \\
\hline Interval D & Stage of continuous growth deceleration corresponding to Bjork stages $6-7$. \\
\hline Interval E & Stage of growth completion indicative of the onset of adulthood corresponding to Bjork stages 8-9. \\
\hline
\end{tabular}

Abbreviation: CVMS, cervical vertebral maturation stage.

Table 4 . The Frequency Distribution of the Maturation Stage of Hand and Wrist Bones in Both Genders

\begin{tabular}{|c|c|c|c|c|c|c|}
\hline \multirow[t]{2}{*}{ Interval } & \multicolumn{2}{|c|}{ Boys } & \multicolumn{2}{|c|}{ Girls } & \multirow[t]{2}{*}{ Total Number } & \multirow[t]{2}{*}{ Total Percentage } \\
\hline & Number & Percentage & Number & Percentage & & \\
\hline $\mathbf{A}$ & 42 & 62.6 & 24 & 36.4 & 66 & 49.6 \\
\hline B & 3 & 4.5 & 9 & 13.6 & 12 & 9 \\
\hline C & 5 & 7.5 & 1 & 1.5 & 6 & 4.5 \\
\hline D & 6 & 9 & 8 & 12.1 & 14 & 10.6 \\
\hline $\mathbf{E}$ & 11 & 16.4 & 24 & 36.4 & 35 & 26.3 \\
\hline
\end{tabular}

The agreement found in patients based on gender is shown in Table 8.

Overall, it seems that, by approaching the growth spurt (11 - 15 years.), the concordance number and the agreement coefficient significantly decrease and vice versa. The concordance number between the two methods was only within the acceptable range in 8- and 9-year-old girls and boys and 10-year-old boys. In other age groups, the agreement between the two methods was not acceptable.

\section{Discussion}

Although, biologically, bone maturation in both genders has a closer correlation than the chronological age with pubertal growth spurt, hand-wrist radiographs are not completely suitable for this purpose due to the following reasons:

1. Bones constantly undergo changes during their maturation, and hand-wrist radiography, as a small part of this system, cannot be representative of the entire skeletal system.

2. In contrast to the chronological age, which is highly accurate, skeletal age has a range of error of about \pm 6 months.

3. Moore (23) also added that facial bones are different from the skeletal system in the rest of the body because facial bones are formed by intramembranous ossification without cartilaginous precursors. Thus, compared to overall body growth, different factors are involved in facial growth. Moreover, craniofacial structures include numerous functional sites with variable responses to environmental and systemic factors.

Based on all of the above, a general consensus has been reached that data regarding skeletal age determination are not very valuable for orthodontic purposes, particularly for girls $(18,24)$. Such differences between the two genders are due to the significant differences in the hormonal balance affecting skeletal ossification, general growth, and secondary sexual characteristics. Another reason discussed by Flores-Mir et al. in 2006 (25) was the effect of the level of maturation. They stated that methods based on the correlation of growth spurts and percentages of remaining growth (such as maturation prediction method described by Fishman [FMP method]) are much more accurate than those evaluating only the skeletal age. They reviewed reports regarding the correlation of the two methods in different ethnic groups with equal conditions and concluded that, due to the effect of this factor, the ossification events method (usually done via radiographic assessment) has less applicability for the prediction of pubertal growth spurts, and the analytical technique influenced by the level of maturation as much as by the ossification events is recommended instead. Using these analyses and not relying solely on the skeletal age decreases the confounding effects of environmental and ethnic factors. In most cases, focusing on the growth velocity and the per- 
Table 5. The Frequency Distribution of the CVMS in Both Genders

\begin{tabular}{|c|c|c|c|c|c|c|}
\hline \multirow[t]{2}{*}{ Stage } & \multicolumn{2}{|c|}{ Boys } & \multicolumn{2}{|c|}{ Girls } & \multirow[t]{2}{*}{ Total Number } & \multirow[t]{2}{*}{ Total Percentage } \\
\hline & Number & Percentage & Number & Percentage & & \\
\hline $\mathbf{1}$ & 23 & 34.3 & 16 & 24.2 & 39 & 29.3 \\
\hline 2 & 21 & 31.3 & 20 & 30.3 & 41 & 30.8 \\
\hline 3 & 10 & 14.9 & 7 & 10.6 & 17 & 12.8 \\
\hline 4 & 9 & 13.4 & 13 & 19.7 & 22 & 16.5 \\
\hline 5 & 4 & 6 & 10 & 15.1 & 14 & 10.5 \\
\hline
\end{tabular}

Abbreviation: CVMS, cervical vertebral maturation stage.

Table 6. The Kappa Coefficient Between the Hand-Wrist Bone Maturation Stage and CVMS in the Understudy Patients

\begin{tabular}{lccc}
\hline & Boys & Girls & Total \\
\hline Number of subjects & 67 & 66 & 133 \\
Percentage of agreement & 50.8 & 42.5 & 46.7 \\
Kappa (95\% CI) & $0.332(0.244-0.380)$ & $0.271(0.178-0.346)$ & $0.312(0.290-0.377)$ \\
\hline
\end{tabular}

Abbreviations: $\mathrm{CI}$, confidence interval; CVMS, cervical vertebral maturation stage.

Table 7. The Agreement Between the Hand-Wrist Bone Maturation Stage and CVMS in Different Age Groups (All Understudy Subjects)

\begin{tabular}{|c|c|c|c|c|}
\hline Age Group & Number & Concordance Number & Proportion of Agreement & 95\% CI for Proportion of Agreement \\
\hline 8 & 10 & 9 & 0.9 & $(0.596-0.982)$ \\
\hline 9 & 18 & 14 & 0.78 & $(0.548-0.910)$ \\
\hline 10 & 16 & 8 & 0.5 & $(0.280-0.720)$ \\
\hline 11 & 14 & 5 & 0.36 & $(0.163-0.612)$ \\
\hline 13 & 13 & 4 & 0.31 & $(0.126-0.576)$ \\
\hline 14 & 11 & 2 & 0.18 & $(0.05-0.476)$ \\
\hline 15 & 10 & 3 & 0.3 & $(0.10-0.603)$ \\
\hline 16 & 10 & 6 & 0.6 & $(0.312-0.831)$ \\
\hline 17 & 10 & 4 & 0.4 & $(0.168-0.687)$ \\
\hline 18 & 10 & 5 & 0.5 & $(0.236-0.7634)$ \\
\hline
\end{tabular}

Abbreviations: $\mathrm{CI}$, confidence interval; CVMS, cervical vertebral maturation stage.

centage of remaining growth neutralizes the effects of gender differences (such as the difference in the onset of skeletal puberty).

In recent years, due to the limitations of hand-wrist radiography and in order to prevent overexposure, the correlation between the CVMS and peak growth spurt (first described by Lamparski) has gained increasing attention. CVM has proven to be an effective and reliable method for the assessment of the skeletal maturation of the mandible in children $(9,10,14)$.
Chen et al., in their study (26), used CVM for the prediction of mandibular length for the first time using a regression equation, then compared it with 2 conventional techniques (growth percentage and growth potential). They reported that the cervical vertebrae method had higher accuracy and prediction power due to the following:

1. Growth potential and growth percentage are methods based on skeletal age analysis and hand-wrist radiographs that include 9 stages for describing the level of maturation of bones. Using an interrupted measure for the 
Table 8. The Agreement Between the Hand-Wrist Bone Maturation Stage and CVMS in Different Age Groups [Girls (G) and Boys (B)]

\begin{tabular}{|c|c|c|c|c|c|c|c|c|}
\hline \multicolumn{5}{|c|}{ Girls } & \multicolumn{4}{|c|}{ Boys } \\
\hline Age Group & Number & $\begin{array}{l}\text { Concordance } \\
\text { Number }\end{array}$ & $\begin{array}{l}\text { Agreement } \\
\text { Coefficient }\end{array}$ & $\begin{array}{l}\text { 95\% CI for } \\
\text { Proportion of } \\
\text { Agreement }\end{array}$ & Number & $\begin{array}{c}\text { Concordance } \\
\text { Number }\end{array}$ & $\begin{array}{r}\text { Agreement } \\
\text { Coefficient }\end{array}$ & $\begin{array}{l}\text { 95\% CI for } \\
\text { Proportion of } \\
\text { Agreement }\end{array}$ \\
\hline 8 & 5 & 4 & 0.8 & $(0.375,0.963)$ & 5 & 5 & 1 & $(0.565,1)$ \\
\hline 9 & 8 & 6 & 0.75 & $(0.409,0.928)$ & 10 & 8 & 0.8 & $(0.490,0.943)$ \\
\hline 10 & 8 & 2 & 0.25 & $(0.071,0.590)$ & 8 & 6 & 0.75 & $(0.409,0.928)$ \\
\hline 11 & 8 & 3 & 0.37 & $(0.136,0.694)$ & 6 & 2 & 0.33 & $(0.096,0.700)$ \\
\hline 12 & 6 & 1 & 0.17 & $(0.030,0.563)$ & 5 & 1 & 0.2 & $(0.036,0.624)$ \\
\hline 13 & 5 & 2 & 0.4 & $(0.117,0.769)$ & 8 & 2 & 0.25 & $(0.071,0.590)$ \\
\hline 14 & 6 & 0 & 0 & $(0,0.390)$ & 5 & 2 & 0.4 & $(0.117,0.769)$ \\
\hline 15 & 5 & 1 & 0.2 & $(0.0361,0.624)$ & 5 & 2 & 0.4 & $(0.117,0.769)$ \\
\hline 16 & 5 & 3 & 0.6 & $(0.230,0.882)$ & 5 & 3 & 0.6 & $(0.230,0.882)$ \\
\hline 17 & 5 & 3 & 0.6 & $(0.230,0.882)$ & 5 & 1 & 0.2 & $(0.036,0.624)$ \\
\hline 18 & 5 & 3 & 0.6 & $(0.230,0.882)$ & 5 & 2 & 0.4 & $(0.117,0.769)$ \\
\hline
\end{tabular}

Abbreviations: CI, confidence interval; CVMS, cervical vertebral maturation stage.

prediction of the continuous growth of the mandible is not very accurate. However, the regression analysis provides a continuous measure for the accurate assessment of continuous growth of the mandible through evaluation of cervical vertebrae.

2. Due to the proximity of the mandible to the cervical vertebrae, the morphogenesis of the mandible, time-wise, is closer to the morphogenesis of the cervical vertebrae compared to that of hand and wrist bones. Thus, mandibular length probably has a closer relationship to the maturation of cervical vertebrae.

In our study, comparison of the two methods of handwrist radiographic analysis and CVMS for the prediction of pubertal growth stages in 133 girls and boys in different age groups did not show a high agreement. Cohen's Kappa coefficient did not show an acceptable agreement; thus, the two methods cannot be alternatively used $(K=0.29)$. The highest agreement was seen in boys aged 8, 9, and 10 years and in girls aged 8 and 9 years. When approaching puberty, this coefficient significantly decreased to $20 \%$ in boys at the age of 12 and girls at the age of 14 . In general, boys showed higher concordance between the two methods compared to girls.

Our results were in accordance with those of Caltabino et al. in 1990 (22); they evaluated 72 Italian patients. Recent studies have indicated that the correlation coefficients of skeletal maturity, determined based on hand-wrist radiographs and CVMS, are significantly different (42\% - 97\%). This difference may be attributed to factors such as sample size, gender, applied method, and the different levels of maturation of understudy subjects. Flores-Mir et al., in a study conducted in 2006 (25), evaluated the skeletal age of 79 Canadians and reported a moderate correlation between the two methods. They stated that the skeletal level affects the degree of correlation between skeletal maturity determined by different methods and should be considered an influential factor in studies on skeletal maturity.

Our results regarding the higher level of concordance in boys than in girls were in accordance with those of Garcia-Fernandez et al. and Lamparski et al. (9, 15); The study by San Roman et al. in 2002 (8) is probably the only study after 1980 that reported opposite results by showing a higher level of concordance in females.

Our results are aligned with those of Garcia-Fernandez et al. (15) in terms of the reduction in agreement between the two methods when approaching the pubertal growth spurt.

In the clinical setting, due to the wide range of differences in mandibular growth, its correlation with the level of skeletal maturation is not very reliable for making predictions. Although assessment of skeletal maturity may be a reliable tool for research purposes in orthodontics (for groups, not for individuals), it does not offer much predicting power for a single patient (which is the routine clinical situation) (22). Based on our results, the agreement between the hand-wrist and cervical vertebral radiographic analysis for determination of skeletal age was weak, so these two methods cannot be alternatively used for this purpose. This may be due to the effects of the skeletal levels of individuals on the correlation between various meth- 
ods, which may be influenced by environmental factors, ethnicity, and even gender.

\section{Acknowledgments}

There are no acknowledgements.

\section{Footnotes}

Authors' Contribution: All authors participated equally in this study.

Financial Disclosure: None declared.

Funding/Support: This work was financially supported by Tehran University of Medical Sciences. The authors declare that there are no conflicts of interest.

\section{References}

1. Bishara SE. Facial and dental changes in adolescents and their clinical implications. Angle Orthod. 2000;70(6):471-83. doi: 10.1043/00033219(2000)070<0471:FADCIA>2.0.CO;2. [PubMed: 11138651].

2. Hunter CJ. The correlation of facial growth with body height and skeletal maturation at adolescence. Angle Orthod. 1966;36(1):44-54. doi: 10.1043/0003-3219(1966)036<0044:TCOFGW>2.0.CO;2. [PubMed 5218761].

3. Sidlauskas A, Zilinskaite L, Svalkauskiene V. Mandibular pubertal growth spurt prediction. Part one: Method based on the hand-wrist radiographs. Stomatologija. 2005;7(1):16-20.

4. Fishman LS. Chronological versus skeletal age, an evaluation of craniofacial growth. Angle Orthod. 1979;49(3):181-9. doi: 10.1043/00033219(1979)049<0181:CVSAAE>2.0.CO;2. [PubMed: 225970]

5. Houston WJ. Relationships between skeletal maturity estimated from hand-wrist radiographs and the timing of the adolescent growth spurt. Eur J Orthod. 1980;2(2):81-93. [PubMed: 6935063].

6. Kucukkeles N, Acar A, Biren S, Arun T. Comparisons between cervical vertebrae and hand-wrist maturation for the assessment of skeletal maturity. J Clin Pediatr Dent. 1999;24(1):47-52. [PubMed:10709543]

7. Al-Hadlaq AM, Hashim HA, Al-Dosari MA, Al-Hamad A. Interrelationship between dental development, skeletal maturity and chronological age in Saudi male children. Egyptian Dental J. 2008;54(1.1).

8. San Roman P, Palma JC, Oteo MD, Nevado E. Skeletal maturation determined by cervical vertebrae development. Eur J Orthod. 2002;24(3):303-11. [PubMed: 12143094].

9. Lamparski DJ. Skeletal age assessment utilizing cervical vertebrae. University of Pittsburgh, School of Dental Medicine: Pittsburgh;1972.
10. Baccetti T, Franchi L, McNamara JJ. An improved version of the cervical vertebral maturation (CVM) method for the assessment of mandibular growth. Angle Orthod. 2002;72(4):316-23. doi: 10.1043/00033219(2002)072<0316:AIVOTC>2.0.CO;2. [PubMed: 12169031].

11. Hassel B, Farman AG. Skeletal maturation evaluation using cervical vertebrae. Am J Orthod Dentofacial Orthop. 1995;107(1):58-66.

12. Caldas Mde P, Ambrosano GM, Haiter-Neto F. Use of cervical vertebral dimensions for assessment of children growth. J Appl Oral Sci. 2007;15(2):144-7. [PubMed: 19089119].

13. Dalili Z. Application of cervical vertebral maturation stages index in orthodontics. J Dent Med. 2004;17(4):5-11.

14. Proffit WR, Fields Jr HW, Sarver DM. Contemporary orthodontics. Elsevier Health Sciences; 2014.

15. Garcia-Fernandez P, Torre H, Flores L, Rea J. The cervical vertebrae as maturational indicators. J Clin Orthod. 1998;32(4):221-5. [PubMed: 9709621].

16. Kimura K. Skeletal maturity of the hand and wrist in Japanese children by the TW2 method. Ann Hum Biol. 1977;4(4):353-6.

17. Mitani H, Sato K. Comparison of mandibular growth with other variables during puberty. Angle Orthod. 1992;62(3):217-22. doi: 10.1043/0003-3219(1992)062<0217:COMGWO>2.0.CO;2. [PubMed: 1416242].

18. Smith RJ. Misuse of hand-wrist radiographs. Am J Orthod. 1980;77(1):75-8. [PubMed: 6928086].

19. Todd T, Pyle S. Quantities study of the vertebral column. Am J Phys Anthropol. 1928;12(321).

20. Grave KC, Brown T. Skeletal ossification and the adolescent growth spurt. Am J Orthod. 1976;69(6):611-9. [PubMed: 179326]

21. Bjork A, Helm S. Prediction of the age of maximum puberal growth in body height. Angle Orthod. 1967;37(2):134-43. doi: 10.1043/00033219(1967)037<0134:POTAOM>2.0.CO;2. [PubMed: 4290545].

22. Caltabiano M, Leonardi R, Zaborra G. [Evaluation of cervical vertebrae for determination of skeletal age]. Riv Ital Odontoiatr Infant. 1990;1(3):15-20. [PubMed: 2076431].

23. Moore RN, Moyer BA, DuBois LM. Skeletal maturation and craniofacial growth. Am J Orthod Dentofacial Orthop. 1990;98(1):33-40.

24. Flores-Mir C, Nebbe B, Major PW. Use of skeletal maturation based on hand-wrist radiographic analysis as a predictor of facial growth: a systematic review. Angle Orthod. 2004;74(1):118-24. doi: 10.1043/00033219(2004)074<0118:UOSMBO>2.0.CO;2. [PubMed: 15038500].

25. Flores-Mir C, Burgess CA, Champney M, Jensen RJ, Pitcher MR, Major PW. Correlation of skeletal maturation stages determined by cervical vertebrae and hand-wrist evaluations. Angle Orthod. 2006;76(1):15. doi:10.1043/0003-3219(2006)076[0001:COSMSD]2.0.CO;2.[PubMed: 16448261].

26. Chen F, Terada K, Hanada K. A new method of predicting mandibular length increment on the basis of cervical vertebrae. Angle Orthod. 2004;74(5):630-4. doi: 10.1043/00033219(2004)074<0630:ANMOPM>2.0.CO;2. [PubMed: 15529497]. 